\title{
Trends in the Mortality Risk of Living Alone during Old Age in Sweden, I992-20 I I
}

Journal of Aging and Health

2020, Vol. 0(0) I-10

(C) The Author(s) 2020

Article reuse guidelines:

sagepub.com/journals-permissions

DOI: I0.I I77/0898264320930452 journals.sagepub.com/home/jah @SAGE

\author{
Benjamin A. Shaw, $\mathbf{P h D}^{\prime}\left(\mathbb{D}\right.$, Lena Dahlberg, $\mathbf{P h D}^{2,3} \mathbb{1}$,

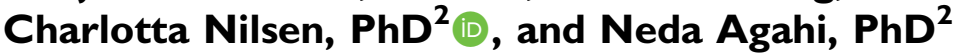

\begin{abstract}
Objectives: This study investigates the association between living alone and mortality over a recent 19-year period (1992$20 \mathrm{II}$ ). Method: Data from a repeated cross-sectional, nationally representative (Sweden) study of adults ages 77 and older are analyzed in relation to 3-year mortality. Results: Findings suggest that the mortality risk associated with living alone during old age increased between 1992 and 2011 ( $p=.076)$. A small increase in the mean age of those living alone is partly responsible for the strengthening over time of this association. Throughout this time period, older adults living alone consistently reported poorer mobility and psychological health, less financial security, fewer social contacts, and more loneliness than older adults living with others. Discussion: Older adults living alone are more vulnerable than those living with others, and their mortality risk has increased. They may have unique service needs that should be considered in policies aiming to support aging in place.
\end{abstract}

\section{Keywords}

living alone, mortality, temporal trends, Sweden

\section{Introduction}

In recent decades, the number of older adults living alone in many high-income countries has increased substantially (Administration on Aging, 2015; DeVaus \& Qu, 2015; Reher \& Requena, 2018; World Health Organization, 2015). This pattern is now accompanied by a growing recognition of the health risks associated with living on one's own during later life (Pimouguet et al., 2016). While living alone during later life is, in some cases, an indication of relatively good physical functioning (Covinsky, 2013; Ennis et al., 2014; HenningSmith \& Gonzales, 2019), several studies have also shown that, over time, living on one's own in later life is a precursor to the development of poor health and increased risk for premature mortality (Gale et al., 2018; Kharicha et al., 2007; Lindstrom \& Rosvall, 2019; Pimouguet et al., 2016; Udell et al., 2012). In fact, the mortality risk associated with living alone has been found to be of a similar magnitude to that of other well-established risk factors, such as obesity, substance abuse, physical inactivity, and mental health problems (HoltLunstad et al., 2015).

Based on a national study of older adults in Sweden, the purpose of this study was to address two related questions. First, we examine whether the mortality risk associated with living alone during old age has grown or declined in recent decades. Second, we examine several potential explanations for observed temporal patterns in the mortality risk associated with living alone during old age, such as the changing demographic profile of this population, potential changes in their health and functional status, as well as the changing socioeconomic status, social relations, and health behaviors of this population.

\section{The Changing Demographics of Solitary-Living Older Adults}

Increases in the number of single-person households occupied by older adults have been apparent throughout much of Europe and the USA since the latter half of the 20th century (Tomassini et al., 2004; World Health Organization, 2015). Sweden is not an exception, as approximately $47 \%$ of Swedish adults aged 75 and older (31\% of men and 59\% of women) are currently living alone (Statistics Sweden, 2018). In recent years, the rise in single-person households has been particularly evident among older men (75+) in Sweden, with a $10 \%$ increase in 5 years for men, and almost no change for women (Statistics Sweden, 2018).

\footnotetext{
'University at Albany (State University of New York), Rensselaer, NY, USA ${ }^{2}$ Karolinska Institutet and Stockholm University, Stockholm, Sweden ${ }^{3}$ Dalarna University, Falun, Sweden

Corresponding Author:

Benjamin A. Shaw, PhD, School of Public Health, University at Albany, State University of New York, One University Place, Rensselaer I2 I44, NY, USA.

Email: bashaw@albany.edu
} 
Increasing life expectancy in both women and men has affected the demographics of solitary living. In particular, it has led to increases in the age at which older people enter into a solitary-living situation due to widowhood (Shaw et al., 2018). Recent increases in male life expectancy (Sundberg et al., 2016; Thorslund et al., 2013), in particular, may be further changing the demographic profile of older adults who are living alone. Traditionally, men have been more likely than women to live alone at younger ages, but this difference reverses in old age because of gender differences in longevity and because women tend to marry older men (Jamieson \& Simpson, 2013). However, as gender differences in longevity lessen, the likelihood that older men will become widowed, and left to live alone during old age, increases. With more older people, and more men comprising the population of solitary-living older adults, overall survival rates in this group should be expected to decline because, even at old ages, survival rates among men continue to lag behind that of women, at least until about age 90 (Jacobs et al., 2014).

\section{Changing Health and Functional Status of Solitary-Living Older Adults}

Despite a gradual decline in disability among older Swedes, in general, since the 1990s (Angleman et al., 2015), recent cohorts of older adults who live alone may be increasingly disadvantaged with regard to functional and social status (Shaw, et al., 2018), key sources of vulnerability according to Mechanic and Tanner (2007). That is, while the health, function, and mortality risk of older Swedes in general may be improving over time - perhaps due to increased levels of education and improvements in medical care - declines in the health and functional status of the population of solitaryliving older adults, in particular, may be also observed as a result of new policies enacted to control the costs of caring for the aging population.

The welfare state in Sweden and other northern European countries has historically provided universal and generous social protection to its citizens, with no formal reliance on caregiving from family and friends (Esping-Andersen, 2013). With increasing demand for long-term care stemming from population aging, many welfare states, including Sweden, are promoting aging in place as an alternative to residential/ institutional care for its older population (Murphy \& Grundy, 2003; Schön et al., 2016). Aging-in-place policies have been present in Sweden since the 1950s. However, circumstances have changed since the late 1990s due to substantial cutbacks in institutional care, covering $21.7 \%$ of older adults aged $80+$ in the year 2000 compared to $11.9 \%$ in 2018 (National Board of Health and Welfare, 2014, 2019). This decline means that not all people with substantial support needs have access to institutional care. As this decline has not been compensated for by an equivalent increase in home help coverage, there is now a greater reliance on help from informal caregivers (Dahlberg, Berndt et al., 2018; Szebehely, \& Trydegård, 2012; Ulmanen \&
Szebehely, 2015). Prior research indicates that many of the individuals who remain on their own in the community as a result of new limitations in institutional care are increasingly disadvantaged in terms of health and functional status and previously would have qualified for institutional care (Schön et al., 2016; Shaw et al., 2018). As such, over time, one should expect to see a decrease in survival among those living alone in old age.

\section{Changing Socioeconomic Status, and Social and Behavioral Factors of Solitary-Living Older Adults}

Finally, it is also possible that trends in the mortality risk associated with living alone in old age are reflective of changes over time in the socioeconomic status and social conditions of older adults who live alone, as well as their health behaviors. For instance, recent research suggests that low socioeconomic status is increasingly linked with living alone, particularly for men (Shaw et al., 2018). Socioeconomic disadvantage across the adult life course, including old ages, is well known to have direct influences on both health and survival (Fors \& Thorslund, 2015), as well as indirect influences via health risk behaviors (Agahi et al., 2018; Balaj et al., 2017; Lewer et al., 2020; Shaw et al., 2014). Therefore, an increasing concentration of socioeconomic disadvantage within the group of older adults who live alone may translate into a worsening health behavior profile for this group, and this may help to explain an increase over time in the mortality risk associated with living alone.

Furthermore, due to societal trends toward smaller family size, increases in divorce, and expanded geographic dispersal of family members (Dykstra, 2009; Honigh-de Vlaming et al., 2014), today's older adults who live alone may be experiencing greater social isolation, less social support, and more loneliness than did previous cohorts of older adults who lived alone (Shaw et al., 2018). According to recent research in this area, overall levels of loneliness have remained relatively stable among older adults in Sweden during the past two decades (Dahlberg, Agahi et al., 2018; see also Eloranta et al. (2015), Nyqvist et al. (2017), Victor et al. (2002)), but recent trends in social isolation and social support are less clear. Like socioeconomic disadvantage, low levels of social integration and support can have direct influences on health and survival (Courtin \& Knapp, 2017; Holt-Lunstad et al., 2015), and may also operate indirectly via health behaviors, in this case by making absent the social control mechanisms that may otherwise steer individuals toward a healthy lifestyle (August $\&$ Sorkin, 2010).

In the analyses that follow, we estimate the degree to which the mortality risk of living alone during old age in Sweden has changed in recent decades, and, if so, whether the observed changes over time in mortality risk can be explained by the changing demographic, health and functional, and social and behavioral factors of successive cohorts of older adults who have lived alone in Sweden during this same period. 


\section{Method}

\section{Sample}

Data are based on face-to-face interviews from the Swedish Panel Study of Living Conditions of the Oldest Old (SWEOLD) (Lennartsson et al., 2014). SWEOLD is a survey of adults aged 77 and older living in Sweden. The SWEOLD sample was extracted from the Swedish Level of Living Survey (LNU), a nationally representative, random probability sample of 6500 adults aged $15-75$, originally fielded in 1968. SWEOLD, which began in 1992, includes all individuals who were part of the LNU sample but who were dropped from the sample after age 75. SWEOLD was administered in the same fashion in 2002 and 2011, as new cohorts of older adults reached the LNU age ceiling. Thus, the data for this study are from three distinct administrations of the SWEOLD survey $(1992,2002$, and 2011) with response rates ranging from $95.4 \%$ in 1992 to $84.4 \%$ in 2002 and $86.2 \%$ in 2011 . These data provide comparable information on the oldest old in Sweden across two decades and allow us to investigate changes in the characteristics and consequences of older people living alone with a repeated cross-sectional design.

A total of 2089 interviews were conducted. Our study excluded individuals living in institutions $(n=328)$ because the focus of the study is older community-dwelling individuals. In addition, because the focus of this study was on the mortality risk of living alone, we excluded proxy interviews $(n=150)$ and individuals who died during the first 100 days of follow-up $(n=14)$, as it was assumed that, for these individuals, any mortality risk associated with their living arrangements would be confounded by an underlying serious health problem. Another seven persons were excluded from all analyses because they were missing information about their living situation. These exclusions resulted in a sample of 1590 individuals across the three observation periods who we use to explore temporal trends in living alone. As expected, excluded individuals were older; more likely to be women; more likely to have died during follow-up; had poorer self-rated health, more mobility problems, and more psychological distress; and were also lonelier and engaged in less social contact than included individuals. There were however no differences between included and excluded individuals with regard to living alone, smoking, education level, and financial difficulties. For analyses examining the mortality risk of living alone, individuals with missing information on any of the included variables $(n=72)$ were also excluded, resulting in a sample of 1518 individuals across the three observation periods for the analyses. Because 77-year-olds were undersampled in the SWEOLD 1992 and men aged 85-99, as well as women aged 90-99, were oversampled in the SWEOLD 2011, sampling weights were used for all analyses.

\section{Measures}

The two focal variables in this study are living alone status and mortality status. To measure living alone status, we used a question asking respondents if they live alone (yes; no). Mortality status was obtained via the Swedish National Cause of Deaths Registry. For each wave of SWEOLD, time under risk was calculated in days from the interview until death or censoring approximately 3 years later (mean follow-up time about 1240 days for each of the data collections). Because 3 years was the maximum duration of follow-up that we were able to achieve for our most recent cohort (i.e., survey administration in 2011), we limited follow-up to 3 years for the earlier cohorts as well so that follow-up times were equivalent in all cohorts. Demographic covariates used in this study include age (years since birth) and gender (male; female). Age and gender were taken from registers during the sampling procedure, and both were then confirmed during the interviews. Health and functional covariates include self-rated health, psychological distress, and mobility impairment. Selfrated health was measured with a question about how the respondent perceived his/her general health (response options: good (0); neither good nor bad (0); bad (1)). Psychological distress was measured with a question about whether respondents had experienced any of the three following conditions/ symptoms in the 12 months preceding the interview: anxiety/ nervousness, depression, or mental illness (response options: no (0); mild (1); severe (2)). A summary score ranging $0-6$ was created. Mobility impairment was defined as the inability to walk $100 \mathrm{~m}$ without difficulties (yes; no), or the inability to go upstairs and downstairs without difficulties (yes; no), added into a scale ranging $0-2$.

Socioeconomic, social, and behavioral covariates used include education level, financial insecurity, social contacts, loneliness, and current smoking. Education level was measured by asking respondents to report their highest level of education and then categorized to distinguish between those who completed grade school only ("low education") and those whose education extended beyond grade school. Financial insecurity was assessed with a measure of "cash margin," which assesses one's ability to acquire a certain amount of money (adjusted for inflation between waves; equivalent to about US\$1500-2000) in one week from his/ her own bank account. Those who were not able to raise this level of funding in this way were defined as financially insecure. A measure of social contacts was constructed from a summary score of four items about the frequency of visiting, or being visited by, friends or relatives (never (0); sometimes (1); often (2)). Scores ranged from 0 to 8 on this scale. Loneliness was measured with the question "Are you ever bothered by feelings of loneliness?," with four response options that were collapsed into frequently lonely (nearly always; often (1)) and rarely lonely (seldom; almost never (0)). Individuals who reported being either light smokers $(<10$ cigarettes per day) or heavy smokers $(10$ or more 
cigarettes per day) were defined as current smokers and were compared to former and never-smokers.

\section{Analysis}

First, we present descriptive statistics (means and prevalence rates) for our key study variables in each year of SWEOLD. This provides information about how rates of living alone and mortality, as well as each covariate, have changed in Sweden since 1992. Results are examined separately for older adults who lived alone in each year of the survey $(1992,2002$, and 2011) and those who lived with others in order to see how the prevalence of each covariate has changed within each subgroup. Each covariate is regressed over time (measured as "years prior to 2011"; time $=0$ in 2011 and time $=19$ in 1992) as a way of statistically testing for temporal trends. Some additional variables were tested in this way but dropped from the study if they showed no evidence of change over time and no difference between those living alone and those living with others (e.g., activities of daily living).

Next, we combine the data from each year of the SWEOLD and run a series of adjusted Cox regression models. In the first model, we estimate the hazard ratio for living alone, while also adjusting for time and estimating the interaction between living alone and time (again, measured as "years prior to 2011"). The interaction shows whether the mortality risk of living alone has changed over time. In subsequent models, the main effect of living alone and its interaction with time are reestimated after adding several covariates (i.e., demographics factors, health and functional status, socioeconomic variables, and social and behavioral factors). Assessing how the estimates of the main effect of living alone and its interaction with time change, or attenuate, with the addition of covariates can tell us the degree to which the covariates explain, or account for, the mortality risk of living alone and the change over time in this mortality risk. Although the SWEOLD study is primarily a repeated crosssectional design, some respondents who are long-term survivors have been included in the study at more than one year of data collection. Therefore, the Huber-White sandwich estimator of variance (Hardin \& Hilbe, 2012) was used to account for intraindividual correlations. All analyses were run in Stata 15.

\section{Results}

Table 1 presents the means and percentages of each key variable at each of the three SWEOLD surveys. More than half of the sample was living alone at each time point. Mortality rates declined over the study period, but this decline was statistically significant only among the populations who were living with others. In particular, whereas $23.7 \%$ of the sample who lived with others in 1992 had died after the 3year follow-up period, only $13.7 \%$ of the sample who lived with others in 2011 had died after the follow-up period ( $p=$ .013). In contrast, those who lived alone had similar mortality risk in 1992 (20\%) and 2011 (18.7\%). Taken together, these trends indicate that mortality was slightly more common among older adults who lived with others compared to those who lived alone in 1992 , but by 2011 , mortality was more common among older adults who lived alone.

Table 1 also shows that the average age of those living alone tends to be higher than the average age of those living with others $(p<.001)$, and this age gap has increased over time $(p=.026)$ due to increases in the average age of individuals who are living alone. Living alone has also been persistently more common among older women than men during this time period $(p<.001)$.

Older adults living alone tend to be disadvantaged compared to those living with others, with regard to health and functional status and socioeconomic status, and in terms of several social and behavioral factors. In particular, those who live alone report higher rates of mobility impairment ( $p \leq$ $.001)$ and more psychological distress $(p<.001)$ than those who live with others. Living alone is also associated with lower levels of education ( $p=.016$ ), more financial insecurity $(p<.001)$, as well as fewer social contacts $(p<.001)$, and more loneliness $(p<.001)$ than living with others.

In Table 2, the association between living alone and mortality is further examined by estimating the hazard ratio associated with living alone and assessing how this hazard ratio changes after adding covariates to the model. Model 1 in Table 2 is the base model and shows the association between living alone and mortality in 2011 (when time $=0$ ) while also estimating an interaction between time and living alone. The results from this model highlight a potential interaction between living alone and time (1992 vs. 2011), indicating that the association between living alone and mortality was different in 1992 than $2011(p=.076)$. The nature of this possible interaction is further represented in Figure 1, which presents the three-year cumulative mortality percentages by living arrangement from Table 1, overlaid with the crude mortality hazard ratios for living alone, stratified by survey year. Although this interaction does not meet traditional thresholds for declaring statistical significance, the basic pattern emerging suggests an increasing mortality risk associated with living alone over time. Again, it should be noted that while the percentage of deaths among those living alone has decreased from 1992 to 2011, an even larger decrease in percentage of deaths was observed over the same time among those who lived with others (from $23.7 \%$ in 1992 to $13.7 \%$ in 2011). This means that, relative to those who lived with others, the mortality risk among those who lived alone has, indeed, increased over time. The interaction between living alone and time that is presented in Model 1 simply picks up on this relative increase in mortality risk among those living alone compared to those living with others.

In Model 2, Table 2, age and gender are added to this base model. In supplemental analyses (not shown here), we tested for gender differences in the association between living alone and mortality but found no evidence of statistically significant differences. In Model 2, both age and male gender are 


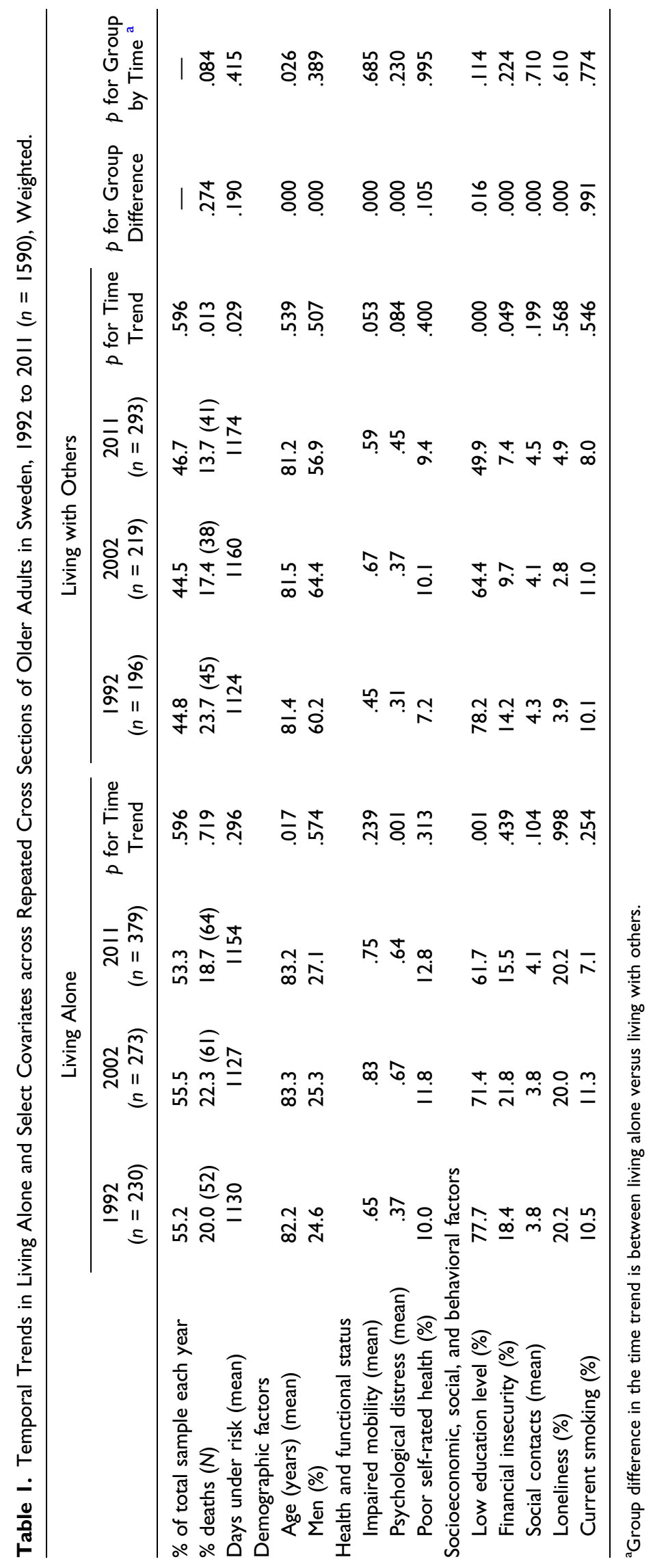


Table 2. Mortality Risk Associated with Living Alone and Covariates: Adults Aged 77 and Older in Sweden, 1992 to $201 \mathrm{I}(n=15 \mathrm{I})$. Hazard Ratios, 95\% Confidence Intervals, and $p$-Values.

\begin{tabular}{|c|c|c|c|}
\hline & MI & $M 2$ & M3 \\
\hline Living alone (ref = living with others) & $1.49(1.02,2.18), p=.039$ & $1.37(.92,2.05), p=.126$ & $1.34(.88,2.02), p=.172$ \\
\hline$\%$ Change from $\mathrm{MI}^{\mathrm{a}}$ & - & -8.1 & -10.1 \\
\hline Time (years prior to $20 \mathrm{II}$ ) & $1.03(1.01,1.06), p=.012$ & $1.03(1.01,1.06), p=.012$ & $1.04(1.01,1.07), p=.004$ \\
\hline Living alone $\times$ time & $.97(.94,1.00), p=.076$ & $.98(.95,1.01), p=.212$ & $.97(.94,1.01), p=.139$ \\
\hline Age & & $1.10(1.07,1.13), p=.000$ & $1.09(1.06,1.12), p=.000$ \\
\hline Men (ref = women) & & $1.52(1.17,1.96), p=.002$ & $1.63(1.25,2.12), p=.000$ \\
\hline Impaired mobility & & & $1.65(1.41,1.93), p=.000$ \\
\hline Psychological distress & & & $.97(.85,1.12), p=.720$ \\
\hline Poor self-rated health (ref = women) & & & $1.61(1.15,2.25), p=.006$ \\
\hline Low education level (ref = beyond grade school) & & & $.98(.75,1.28), p=.894$ \\
\hline Financial insecurity (ref = financially secure) & & & $.94(.65,1.35), p=.736$ \\
\hline Social contact & & & $.96(.89,1.03), p=.252$ \\
\hline Loneliness (ref $=$ seldom/almost never) & & & $.85(.57,1.28), p=.448$ \\
\hline Smoking (ref = nonsmoking) & & & $1.27(.82,1.98), p=.289$ \\
\hline
\end{tabular}

${ }^{a}[\ln (H R M x)-\ln (H R M I)] / \ln (H R M I) \times 100$.

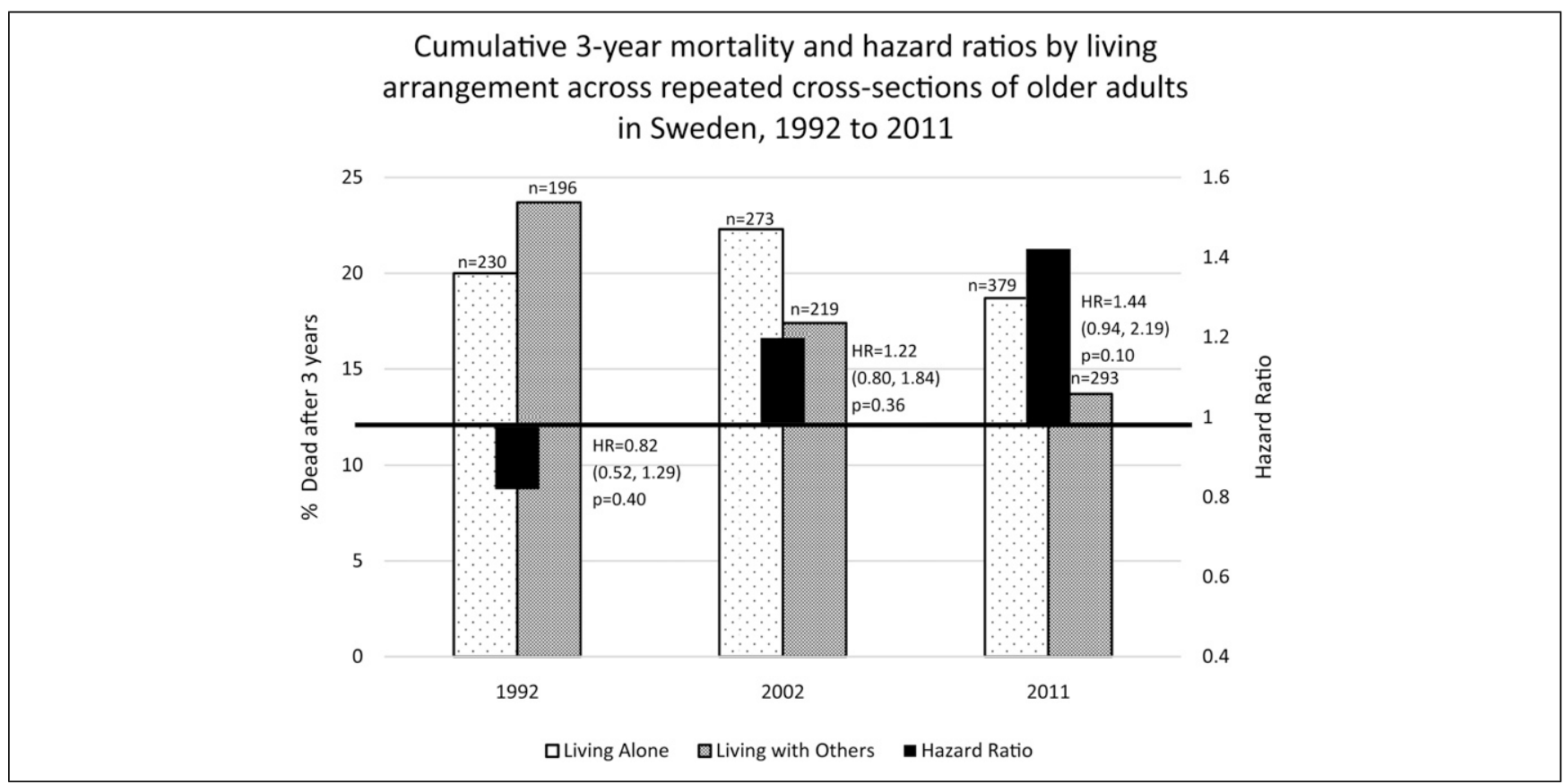

Figure I. Three-year cumulative mortality by living arrangement, as well as mortality hazard ratios and $95 \%$ confidence intervals for living alone across repeated cross sections of older adults in Sweden, 1992 to 2011.

associated with increased risk for mortality. And, with age and gender in the model, the hazard ratio for living alone declines by $8.1 \%$, indicating that $8 \%$ of the mortality risk of living alone is accounted for by age and gender differences across living arrangements (i.e., those living alone are older). Also in Model 2, the interaction between living alone and time (1992 vs. 2011) is somewhat attenuated, an indication that the strengthening over time of the association between living alone and mortality may be partially due to the interrelationships among living alone, time, age, and gender. Referring to Table 1 helps us to discern the nature of these interrelationships. In particular, Table 1 shows evidence of a growing age gap between those living alone and those living with others, and a gradual (although not statistically significant) trend toward higher proportions of men among the solitary living.

In Model 3, all other covariates are included in the model. Among these variables, impaired mobility and poor selfrated health are associated with increased risk for mortality. 
Compared to Model 1, this full model produces a $10 \%$ attenuation of the hazard ratio for living alone, with virtually no change in the interaction between living alone and time (1992 vs. 2011). Thus, it seems as if age, and not the other covariates, is primarily responsible for any attenuation of the hazard ratio for living alone and its interaction with time.

\section{Discussion}

Findings from this study provide only modest support for the idea that the association between living alone and mortality has become increasingly strong during recent decades. Whereas rates of mortality have declined steadily between 1992 and 2011 among older adults in Sweden who lived with others (and within the population as a whole), declines in mortality among older adults living alone have lagged behind. Reflecting these trends, the estimated crude hazard ratios of mortality for living alone (versus living with others) grew from 1992 to 2011. While the $p$-value for this latter estimate does not meet the traditional threshold for statistical significance, the estimate of an approximately $44 \%$ increase in mortality risk associated with living alone is in line with the estimates of a growing body of epidemiologic studies that highlight the risk for mortality of living alone and other forms of social disconnection (Holt-Lunstad, 2017; Leigh-Hunt et al., 2017; Rico-Uribe et al., 2018; Smith \& Victor, 2019).

The findings from this study suggest that living alone during old age in Sweden may not have always been a risk factor for elevated mortality. Instead, the risk associated with living alone seems to have emerged around the early 2000s and has grown since then. Still, the change in mortality risk observed in our sample was just above the traditional threshold for statistical significance $(p=.076)$. As such, conclusions about the trend of a growing mortality risk associated with living alone should be made with some degree of caution, but further monitoring of this trend is clearly warranted.

Also warranted is further research examining the factors that may be driving the increases in mortality risk associated with living alone during old age. The findings from this study indicate that growing age disparities between those who live alone and those who live with others may partly explain the observed increase in mortality risk associated with living alone. Between 1992 and 2011, the average age of older adults who lived with others remained stable, but the average age of older adults who lived alone increased by one year such that by 2011, those living alone were, on average, two years older than those living with others. This age difference, along with a slowly growing proportion of older men among the solitary living, accounted for about $8 \%$ of the increased mortality risk associated with living alone that was found in 2011.

It is likely that increases in life expectancy, for both women and men, account for some of the increase over time in the average age of the living-alone group. These increases in life expectancy have increased the average age of widowhood and, thus, have likely increased the average age at which many enter the living alone arrangement. Additionally, increases in the average age of those living alone may be the result of more stringent criteria for entry into institutional care (Schön, et al., 2016). This means that many individuals who are quite vulnerable may no longer qualify for institutional care. Increasing age may be one indicator of this growing vulnerability among those left behind to age in place due to these stricter criteria.

Aside from the increasing age and increasing proportion of men, none of the other factors examined in the current study accounted for the growing mortality risk of living alone. Although those living alone have become more disadvantaged relative to those living with others in some key areas, such as psychological distress and education level, these disparities have evidently not translated into growing disparities in mortality risk.

Beyond changes over time in the age and gender distribution of Sweden's community-dwelling older adults, it is important to consider the degree to which there remains any inherent risk associated with living alone as an older adult. In the current study, the hazard ratio of mortality for living alone decreased to 1.34 in a fully adjusted model. While not statistically significant, this effect size is large enough to suggest that a meaningful risk associated with living alone remains. Prior research suggests that this risk is most likely a function of the social disconnection and loneliness that is likely to be prevalent among those who live alone (Dahlberg, Andersson et al., 2018; Holt-Lundstad, 2017; O'Suilleabhainm et al., 2019). However, in the current study, support for this idea was not found, as the social contact variable included in this study was not independently associated with mortality in the full model.

\section{Limitations}

In considering the findings and implications of this study, some key limitations should be acknowledged. In particular, while the data used in this study have several strengths - for example, they are nationally representative, consistent over a relatively long period of time, and have very low nonresponse rates - they also have certain limitations. For example, because of the repeated cross-sectional design of this study, we are neither able to account for changes in living arrangements that may have occurred after baseline nor estimate the impact that such changes may have had on survival. This is a potential problem for our analysis to the extent that serious health problems are antecedent to a change in living arrangements. In such a case, associations between living arrangements and mortality may, at least in part, be due to a sort of "reverse causation." We have attempted to account for some of the impact of health on living arrangements that may have occurred prior to baseline by excluding proxy interviews as well as excluding individuals who died during the first 100 days of follow-up; however, we are not able to control for health-prompted changes in living arrangements that occurred after baseline. 
The exclusion of proxy interviews, itself, also has limitations that deserve consideration. Clearly, removing proxies from the analysis has the consequence of reducing statistical power. However, all things considered, we are not convinced that including them would improve the analyses. Indeed, we are concerned that including proxies could actually impair our analyses, for at least two main reasons. First, as discussed above, including proxies most likely means that we would be including older adults with serious health conditions, many of whose current living arrangement is a result of their health condition. Because we are most interested in estimating the mortality risk associated with one's living arrangement, we want to limit as much as possible this type of "reverse causation." In addition, including proxies could impair our measurement of key variables. For example, as one of the strongest predictors of mortality, we need a reliable measure of self-rated health. The best way to ensure this is through direct interviews with participants. Proxy assessments of self-rated health would call into question the reliability of this key measure.

Furthermore, we note that it is possible that the processes that lead one to live alone, as well as the processes that transmit risk associated with living alone, may differ by gender (Holwerda et al., 2012; Kandler et al., 2007). Although our data did not reveal significant gender differences in the association between living alone and mortality, further research into this topic is warranted. Risks associated with living alone may also vary according to differences in the nature of the broader social networks surrounding those living alone (Djundeva et al., 2019); therefore, further research examining how social networks may moderate the risk associated with living alone is also warranted. In addition, because in this study we only included variables that were measured consistently across survey waves, with few missing values, we were forced to exclude some covariates that may play an important role in explaining the changing mortality risk of living alone, such as cognitive impairment.

\section{Conclusions}

Taken together, our findings suggest that, over time, living alone as an older adult in Sweden may be increasingly associated with mortality but primarily because the more recent cohorts of solitary-living older adults are older than previous cohorts. Changing policies regarding eligibility for entry into institutional care, which have left in the community more older people who are living alone, may be partly responsible for both of these trends. More work is needed, though, to fully assess the extent to which living alone may also bring with it an inherent risk for mortality, perhaps related to the social disconnection that often comes with this living arrangement. Cutbacks in formal care have made older adults more reliant on informal care, most often provided by a spouse/partner (Dahlberg, Berndt et al. 2018), and this is a source of care not available to individuals living alone. As such, this growing subgroup of the population may have unique service needs that should be taken into consideration in policies aiming to help older adults age in place.

\section{Authors' Note}

This work was supported by Forte, the Swedish Research Council for Health, Working Life and Welfare (grant 2015-01360), and NordForsk (grant 74637). The funding sources had no role in the data collection, analysis and interpretation of data, writing the manuscript, or the decision to submit it for publication. Ethical approvals for the SWEOLD study have been provided by the Uppsala University Hospital (reg. no. 247/91), the Karolinska Institutet Regional Research Ethics Committee (reg. no. 03-413), and the Regional Ethical Review Board in Stockholm (reg. no. 2010/403-31/4).

\section{Author Contributions}

All authors designed the study. Neda Agahi conducted the statistical analyses. All authors contributed to the interpretation of results. Benjamin Shaw led the writing of the manuscript, while Lena Dahlberg, Charlotta Nilsen, and Neda Agahi assisted in writing the manuscript and revising it critically for intellectual content. All approved the final version of the manuscript to be published.

\section{Declaration of Conflicting Interests}

The author(s) declared no potential conflicts of interest with respect to the research, authorship, and/or publication of this article.

\section{Funding}

The authors disclosed receipt of the following financial support for the research, authorship, and/or publication of this article: This work was supported by Forte, the Swedish Research Council for Health, Working Life and Welfare (grant 2015-01360), and NordForsk (grant 74637).

\section{ORCID iDs}

Benjamin Shaw (D) https://orcid.org/0000-0002-4756-495X

Lena Dahlberg (D) https://orcid.org/0000-0002-7685-3216

Charlotta Nilsen (D) https://orcid.org/0000-0003-3662-5486.

\section{References}

Administration on Aging, Administration for Community Living, \& U.S. Department for Health and Human Services. (2015). A Profile of Older Americans: 2015. https://www.acl.gov

Agahi N., Fors S., Fritzell J., \& Shaw BA. (2018). Smoking and physical inactivity as predictors of mobility impairment during late life: Exploring differential vulnerability across education level in Sweden. Journal of Gerontology: Social Sciences, 73(4), 675-683. doi:10.1093/geronb/gbw090

Angleman, S. B., Santoni, G., Von Strauss, E., \& Fratiglioni, L. (2015). Temporal trends of functional dependence and survival among older adults from 1991 to 201 in Sweden: Toward a healthier aging. The Journals of Gerontology: Series A: Biological Sciences and Medical Sciences, 70(6), 746-752. doi: 10.1093/gerona/glu206

August, K. J., \& Sorkin, D. H. (2010). Marital status and gender difference in managing a chronic illness: The function of healthrelated social control. Social Science \& Medicine, 71(10), 1831-1838. doi:10.1016/j.socscimed.2010.08.022 
Balaj, M., McNamara, C. L., Eikemo, T. A., \& Bambra, C. (2017). The social determinants of inequalities in self-reported health in Europe: Findings from the European social survey (2014) special module on the social determinants of health. European Journal of Public Health, 27, 107-114. doi:10.1093/eurpub/ckw217

Courtin, E., \& Knapp, M. (2017). Social isolation, loneliness and health in old age: A scoping review. Health \& Social Care in the Community, 25(3), 799-812. doi:10.1111/hsc.12311

Covinsky, K. E. (2013). The differential diagnosis of living alone. JAMA Internal Medicine, 173(4), 321. doi:10.1001/jamainternmed.2013

Dahlberg, L., Agahi, N., \& Lennartsson, C. (2018). Lonelier than ever? Loneliness of older people over two decades. Archives of Gerontology and Geriatrics, 75, 96-103. doi:10.1016/j.archger. 2017.11.004

Dahlberg, L., Andersson, L., \& Lennartsson, C. (2018). Long-term predictors of loneliness in old age: Results of a 20-year national study. Aging \& Mental Health, 22(2), 190-196. doi:10.1080/ 13607863.2016.1247425

Dahlberg, L., Berndt, H., Lennartsson, C., \& Schön, P. (2018). Receipt of formal and informal help with specific care tasks among older people living in their own home. Nationaltrends over two decades. Social Policy \& Administration, 52(1), 91-110. doi:10.1111/spol.12295

De Vaus, D. A., \& Qu, L. (2015). Demographics of living alone (Australian family trends no. 6). Australian Institute of Family Studies.

Djundeva, M., Dykstra, P.A., \& Fokkema, T. (2019). Is living alone "aging alone"? Solitary living, network types, and well-being. Journals of Gerontology: Social Sciences, 74(8), 1406-1415. doi:10.1093/geronb/gby119

Dykstra, P. A. (2009). Older adult loneliness: Myths and realities. European Journal of Ageing, 6, 91-100. doi:10.1007/s10433009-0110-3

Eloranta, S., Arve, S., Isoaho, H., Lehtonen, A., \& Viitanen, M. (2015). Loneliness of older people aged 70: A comparison of two Finnish cohorts born 20 years apart. Archives of Gerontology and Geriatrics, 61(2), 254-260. doi:10.1016/j.archger. 2015.06.004

Ennis, S. K., Larson, E. B., Grothaus, L., Helfrich, C. D., Balch, S., \& Phelan, E. A. (2014). Association of living alone and hospitalization among community-dwelling elders with and without dementia. Journal of General Internal Medicine, 29(11), 1451-1459. doi:10.1007/s11606-014-2904-z

Esping-Andersen, G. (2013). The three worlds of welfare capitalism. Polity Press.

Fors, S. \& Thorslund, M. (2015). Enduring inequality: Educational disparities in health among the oldest old in Sweden, 1992-2011. International Journal of Public Health, 60(1), 91-98. doi:10. 1007/s00038-014-0646-7

Gale, C. R., Westbury, L., \& Cooper, C. (2018). Social isolation and loneliness as risk factors for the progression of frailty: The English longitudinal study of ageing. Age and Ageing, 47(3), 392-397. doi:10.1093/ageing/afx188

Hardin, J. W., \& Hilbe, J. M. (2012). Generalized linear models and extensions (3rd ed.). Stata Press.

Henning-Smith, C., \& Gonzales, G. (2019). The relationship between living alone and self-rated health varies by age: Evidence from the national health interview study. Journal of Applied Gerontology, 073346481983511. doi:10.1177/0733464819835113
Holt-Lunstad, J. (2017). The potential public health relevance of social isolation and loneliness: Prevalence, epidemiology, and risk factors. Public Policy \& Aging Report, 27(4), 127-130.

Holt-Lunstad, J., Smith, T. B., Baker, M., Harris, T., \& Stephenson, D. (2015). Loneliness and social isolation as risk factors for mortality: A meta-analytic review. Perspectives on Psychological Science, 10(2), 227-237. doi:10.1177/1745691614568352

Holwerda, T. J., Beekman, A. T. F., Deeg, D. J. H., Stek, M. L., van Tilburg, T. G., Visser, P. J., \& Schoevers, R. A. (2012). Increased risk of mortality associated with social isolation in older men: Only when feeling lonely? Results from the Amsterdam study of the elderly (AMSTEL). Psychological Medicine, 42(4), 843-853. doi:10.1017/s0033291711001772

Honigh-de Vlaming, R., Haveman-Nies, A., Groeniger, I. B.-O., de Groot, L., \& van't Veer, P. (2014). Determinants of trends in loneliness among Dutch older people over the period 20052010. Journal of Aging and Health, 26, 422-440. doi:10.1177/ 0898264313518066

Jacobs, J. M., Cohen, A., Ein-Mor, E., \& Stessman, J. (2014). Gender differences in survivals in old age. Rejuvenation Research, 17(6), 499-506. doi:10.1089/rej.2014.1587

Jamieson, L., \& Simpson, R. (2013). Living alone: Globalization, identity, and belonging. Palgrave Macmillon.

Kandler, U., Meisinger, C., Baumert, J., Lowel, H, \& The KORA Study Group (2007). Living alone is a risk factor for mortality in men but not women from the general population: A prospective cohort study. BMC Public Health, 7, 335.

Kharicha, K., Iliffe, S., Harari, D., Swift, C., Gillmann, G., \& Stuck, A. E. (2007). Health risk appraisal in older people: Are older people living alone an 'at-risk' group? The British Journal of General Practice, 57(537), 271-276.

Leigh-Hunt, N., Bagguley, D., Bash, K., Turner, V., Turnbull, S., Valtorta, N., \& Caan, W. (2017). An overview of systematic reviews on the public health consequences of social isolation and loneliness. Public Health, 152, 157-171. doi:10.1016/j. puhe.2017.07.035

Lennartsson, C., Agahi, N., Hols-Salén, L., Kelfve, S., Kåreholt, I., Lundberg, O., Parker, M. G., \& Thorslund, M. (2014). Data resource profile: The Swedish panel study of living conditions of the oldest old (SWEOLD). International Journal of Epidemiology, 43(3), 731-738. doi:10.1093/ije/dyu057

Lewer, D., Jayatunga, W., Aldridge, R. W., Edge, C., Marmot, M., Story, A., \& Hayward, A. (2020). Premature mortality attributable to socioeconomic inequality in England between 2003 and 2018: An observational study. Lancet Public Health, 5(1), E33-E41. doi:10.1016/s2468-2667(19)30219-1

Lindstrom, M., \& Rosvall, M. (2019). Marital status and 5-year mortality: A population-based prospective cohort study. Public Health, 170, 45-48. doi:10.1016/j.puhe.2019.02.015

Mechanic, D., \& Tanner, J. (2007). Vulnerable people, groups, and populations: Societal view. Health Affairs, 26, 1220-1230. doi: 10.1377/hlthaff.26.5.1220

Murphy, M., \& Grundy, E. (2003). Mothers with living children and children with living mothers: The role of fertility and mortality in the period 1911-2050. Population Trends, Summer(112), 36-44.

National Board of Health and Welfare. (2014). Tillstaindet och utvecklingen inom hälso- och sjukvård och socialtjänst: Lägesrapport 2014. [The situation and development of health 
care and social services. Progress report 2014]. https://www. socialstyrelsen.se/globalassets/sharepoint-dokument/artikelkatalog/ ovrigt/2014-2-3.pdf

National Board of Health and Welfare. (2019). Vård och omsorg om äldre. Lägesrapport 2019. [Health and Social Care for Older People. Progress report 2019]. https://www.socialstyrelsen.se/ globalassets/sharepoint-dokument/artikelkatalog/ovrigt/20193-18.pdf

Nyqvist, F., Cattan, M., Conradsson, M., Nasman, M., \& Gustafsson, Y. (2017). Prevalence of loneliness over ten years among the oldest old. Scandinavian Journal of Public Health, 45(4), 411-418. doi:10.1177/1403494817697511

O'Suilleabhain, P. S., Gallagher, S., \& Steptoe, A. (2019). Loneliness, living alone, and all-cause mortality: The role of emotional and social loneliness in the elderly during 19 years of follow-up. Psychosomatic Medicine, 81(6), 521-526. doi:10. 1097/psy.0000000000000710

Pimouguet, C., Rizzuto, D., Schön, P., Shakersain, B., Angleman, S., Lagergren, M., Fratiglioni, L, \& Xu, W. (2016). Impact of living alone on institutionalization and mortality: A population-based longitudinal study. TheEuropean Journal of Public Health, 26(1), 182-187. doi:10.1093/eurpub/ckv052

Reher, D., \& Requena, M. (2018). Living alone in later life: A global perspective. Population and Development Review, 44(3), 427-454. doi:10.1111/padr.12149

Rico-Uribe, L. A., Caballero, F. F., Martin-Maria, N., Cabello, M., Ayuso-Mateos, J. L., \& Miret, M. (2018). Association of loneliness with all-cause mortality: A meta-analysis. Plos One, 13(1), e019003. doi:10.1371/journal.pone.0190033

Schön, P., Lagergren, M., \& Kåreholt, I. (2016). Rapid decrease in length of stay in institutional care for older people in Sweden between 2006 and 2012: Results from a population-based study. Health \& Social Care in the Community, 24(5), 631-638. doi: 10.1111/hsc. 12237

Shaw, B. A., Fors, S., Fritzell, J., Lennartsson, C., \& Agahi, N. (2018). Who lives alone during old age? Trends in the social and functional disadvantages of Sweden's solitary living older adults. Research on Aging, 40(9), 815-838. doi:10.1177/0164027517747120

Shaw, B. A., McGeever, K., Vasquez, E., Agahi, N., \& Fors, S. (2014). Socioeconomic inequalities in health after age 50: Are health risk behaviors to blame? Social Science \& Medicine, 101, 52-60. doi:10.1016/j.socscimed.2013.10.040
Smith, K. J., \& Victor, C. (2019). Typologies of loneliness, living alone and social isolation, and their associations with physical and mental health. Ageing \& Society, 39(8), 1709-1730. doi:10. 1017/s0144686x18000132

Statistics Sweden. (2018). Number of persons by types of household, household status, age and sex: Year 2011-2016. http://www. statistikdatabasen.scb.

Sundberg, L., Agahi, N., Fritzell, J., \& Fors, S. (2016). Trends in health expectancies among the oldest old in Sweden, 19922011. European Journal of Public Health, 26(6), 1069-1074. doi:10.1093/eurpub/ckw066

Szebehely, M., \& Trydegård, G. B. (2012). Home care for older people in Sweden: A universal model in transition. Health \& Social Care in the Community, 20(3), 300-309. doi:10.1111/j. 1365-2524.2011.01046.x

Thorslund, M., Wastesson, J. W., Agahi, N., Lagergren, M., \& Parker, M. G. (2013). The rise and fall of women's advantage: A comparison of national trends in life expectancy at age 65 years. European Journal of Ageing, 10(4), 271-277. doi:10.1007/ s10433-013-0274-8

Tomassini, C., Glaser, K., Wolf, D. A., van Groenou, M. B., \& Grundy, E. (2004). Living arrangements among older people: An overview of trends in Europe and the USA. Population Trends, 115, 24-35. doi:10.1007/s10680-006-9004-7

Udell, J. A., Steg, P. G., Scirica, B. M., Smith, S. C., Ohman, E. M., Eagle, K. A., Goto, S., Cho, J. I., Bhatt, D. L., \& REduction of Atherothrombosis for Continued Health (REACH) Registry Investigators. (2012). Living alone and cardiovascular risk in outpatients at risk of or with atherothrombosis. Archives of Internal Medicine, 172(14), 1086-1095. doi:10.1001/ archinternmed.2012.2782

Ulmanen, P., \& Szebehely, M. (2015). From the state to the family or to the market? Consequences of reduced residential eldercare in Sweden. International Journal of Social Welfare, 24, 81-92. doi:10.1111/ijsw. 12108

Victor, C. R., Scambler, S. J., Shah, S., Cook, D. G., Harris, T., Rink, E., \& de Wilde, S. (2002). Has loneliness amongst older people increased? An investigation into variations between cohorts. Ageing \& Society, 22, 585-597.

World Health Organization. (2015). World Report on Ageing and Health. http:/www.who.int/ageing/events/world-report-2015launch/en/ 